\title{
Einleitung zum Themenheft BALI (Indonesien)
}

Regionaler Forschungsschwerbereich der Fachrichtung Anthropogeographie an der Universität Zürich ist Südostasien, insbesondere Indonesien. Mit den vorliegenden fünf Aufsätzen hoffen die Autoren, den Lesern einen Einblick in sozio-kulturelle und sozio-ökonomische Belange der faszinierenden Insel Bali zu vermitteln und gleichzeitig die Stoßrichtung ihrer Forschung zu verdeutlichen.

Lebensraum der Indonesier ist das Land und das Meer. Nichts könnte dies besser belegen als die einheimische Konzeption von "Heimatland»: tanah air kita ("unser Land und Wasser»). Es war der britische Gelehrte James Richardson Logan, der - dazumal in Singapur niedergelassen - 1850 den Begriff «Indonesien» als Bezeichnung für die immense Inselkette prägte, die in ihrer West-OstAusdehnung von gut einem Achtel des Äquatorumfangs die eurasiatische Landmasse mit dem australischen Kontinent verbindet. Das Wort ist von den beiden griechischen Termini «indos» (der Inder) und "nesoi»(Inseln) abzuleiten.
Als Nachfolgestaat des Niederländisch-Ostindischen Kolonialreichs umfaßt Inselindien 13677 Eilande, von denen allerdings kaum ein Drittel bewohnt sind. Deren Flächen reichen von kleinsten Korallenriffen und Felsklippen bis hin zu Anteilen an den zweit- und drittgrößten Inseln der Welt: Neuguinea $\left(785000 \mathrm{~km}^{2}\right)$ und Borneo $\left(736500 \mathrm{~km}^{2}\right)$. Selbst Sumatra $\left(473660 \mathrm{~km}^{2}\right)$ weist die doppelte Fläche von Großbritannien auf. Gemessen an der Einwohnerzahl ist Indonesien nach China, Indien und den USA der viertbevölkerungsreichste Staat der Welt. Mit 43\% der Bevölkerung (1992: 185 Millionen Menschen) und 42\% der Landfläche (2,027 Millionen $\mathrm{km}^{2}$ ) übertreffen die Dimensionen Inselindiens diejenigen anderer südostasiatischer Länder bei weitem. Zusätzlich beansprucht die Inselrepublik Rechte auf 3,166 Millionen $\mathrm{km}^{2}$ Territorialgewässer. Die Lage beidseits des Äquators (von 6 $48^{\prime}$ n. Br. bis $11^{\circ} 15^{\prime}$ s. Br.) beeinflußt das maritim geprägte Tropenklima des Inselbogens, der im Süden vom Indischen Ozean und im Norden von Teilmeeren des Pazifiks bespült wird.

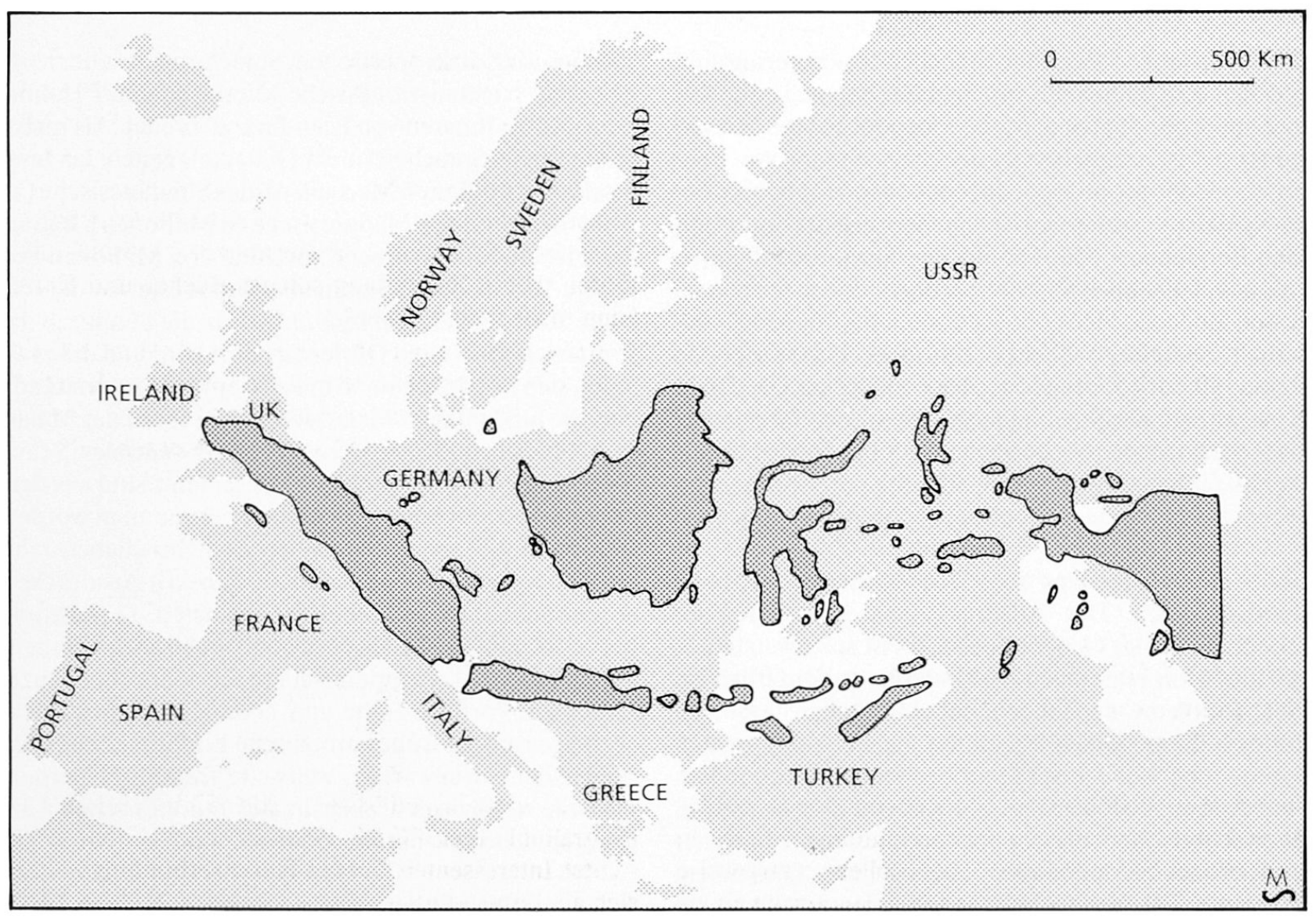

Fig. 1 Größenvergleich zwischen Indonesien und Europa. 


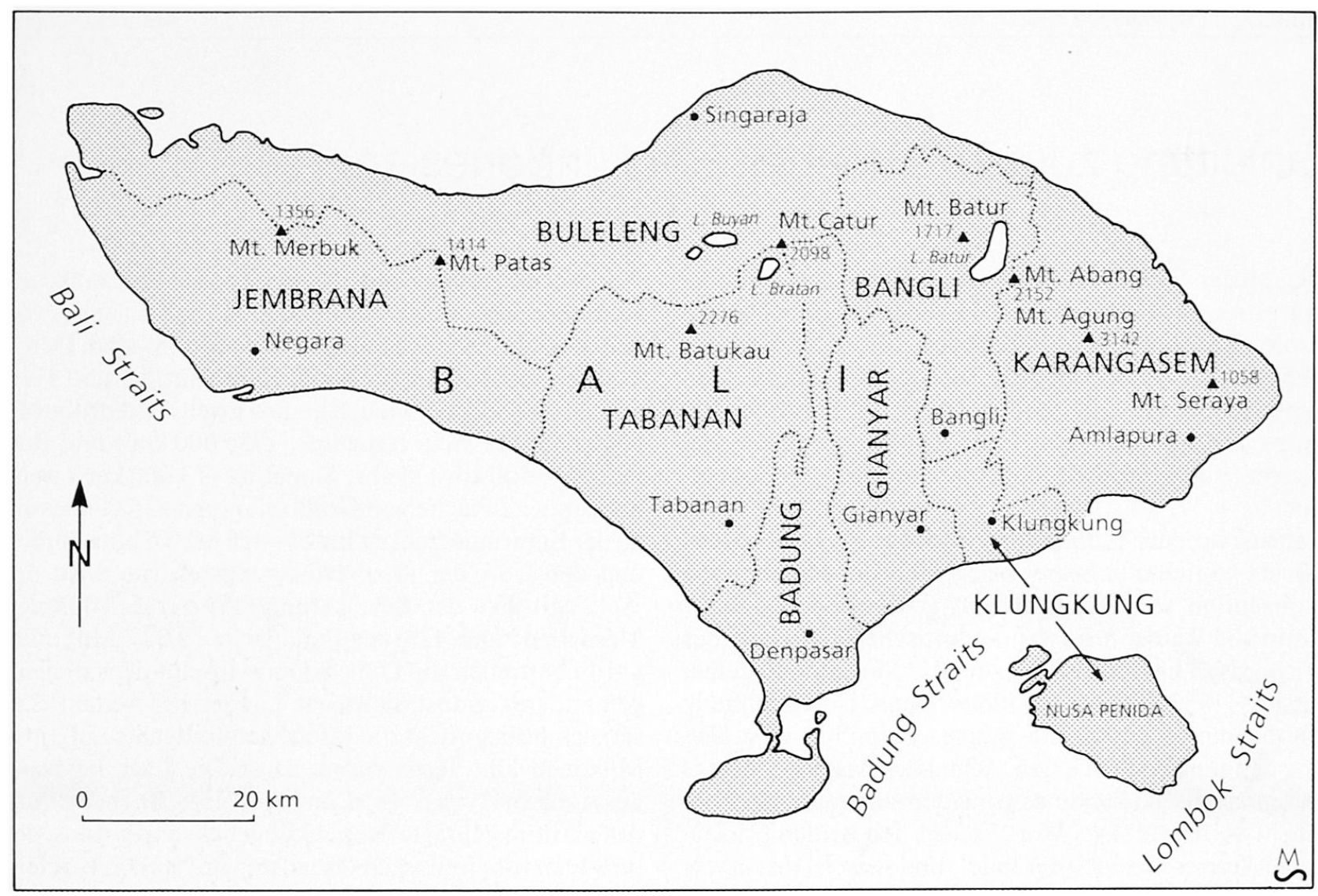

Fig. 2 Karte von Bali.

Da die Distanzen zwischen manchen Inseln gering sind und sie oft in Sichtweite voneinander liegen, ist die See eher ein verbindender als ein trennender Faktor. Wieviel mühsamer ist beispielsweise die Überwindung von Festlandgebieten mit ihren dichtbestockten tropischen Regenwäldern, versumptten Tiefländern und stark zerklüfteten Bergflanken! Die Geschichte belegt die Offenheit Indonesiens gegenüber externen Einflüssen, aber auch dessen Rolle als Herd der Ausstrahlung in Gebiete auBerhalb des heutigen Staatsterritoriums. Angehörige von Fremdvölkern haben sich seit der Frühzeit der Geschichte im großen Archipel niedergelassen, wie andererseits Indonesier beispielsweise an der Ostküste von Madagaskar Fuß faßten, Gewürze nach Sri Lanka verschifften und Beziehungen mit dem Khmerreich von Angkor pflegten.

Der Archipelcharakter schafft aber auch spezifische Schwierigkeiten. Der Ausdruck, daß Indonesien im Kampf mit seiner Geographie stehe, ist so zu verstehen, daß die Natur regionalen Partikularismen förderlich ist. Viele Probleme der jungen Republik haben ihren Ursprung in ihrer starken Zersplitterung, der ausgeprägten Kammerung vieler Inseln und der ethnisch-kulturellen Vielfalt ihrer Bevölkerung. Ein weiterer Teil wurzelt in der wechselvollen Geschichte Indonesiens mit seiner rund 350jährigen kolonialen Vergangenheit. Die frühere Isolierung vieler Gegenden drückt sich unter anderem in den ungefähr 250 Regionalsprachen aus, welche haupt- sächlich der austronesischen Sprachgruppe zuzurechnen sind. Nichtaustronesische Idiome sind auf Halmahera und im Inneren von Irian Jaya verbreitet. Als meistgesprochene Sprachen (nicht Dialekte!) gelten das Javanische (60 Millionen Menschen), das Sundanesische (15 Millionen) und das Maduresische (8 Millionen). Balinesisch ist die Muttersprache von rund drei Millionen Personen. Verbindendes Idiom aller Indonesier ist die offizielle Staatssprache Bahasa Indonesia, die bereits ab der Primarschule in allen Dörfern gelehrt wird und die es erlaubt, sich im ganzen Land in einer Sprache zu verständigen. Sie fußt auf dem Malayischen, wie es auf der Malakka-Halbinsel, im Riau-Archipel und im zentralen Sumatra gesprochen wird. Zusätzliche Elemente sind aus dem Javanischen und Sundanesischen übernommen worden. Indische Einflüsse ab den ersten nachchristlichen Jahrhunderten manifestieren sich in Sanskrit-Ausdrücken. Arabische Lehnwörter sind der ab spätem 13. Jahrhundert erfolgenden Islamisierung und arabischen Handelsaktivitäten in kosmopolitischen Küstenstädten zuzuschreiben. Portugiesische und holländische Ausdrücke verweisen auf die frühe europäische Einflußnahme, während in der Gegenwart der weltweite Trend zur Übernahme von Anglizismen auch in der indonesischen Umgangssprache spürbar ist.

Bali - flächenmäßig mit dem Schweizer Kanton Wallis vergleichbar - ist die westlichste der Kleinen Sunda-In- 


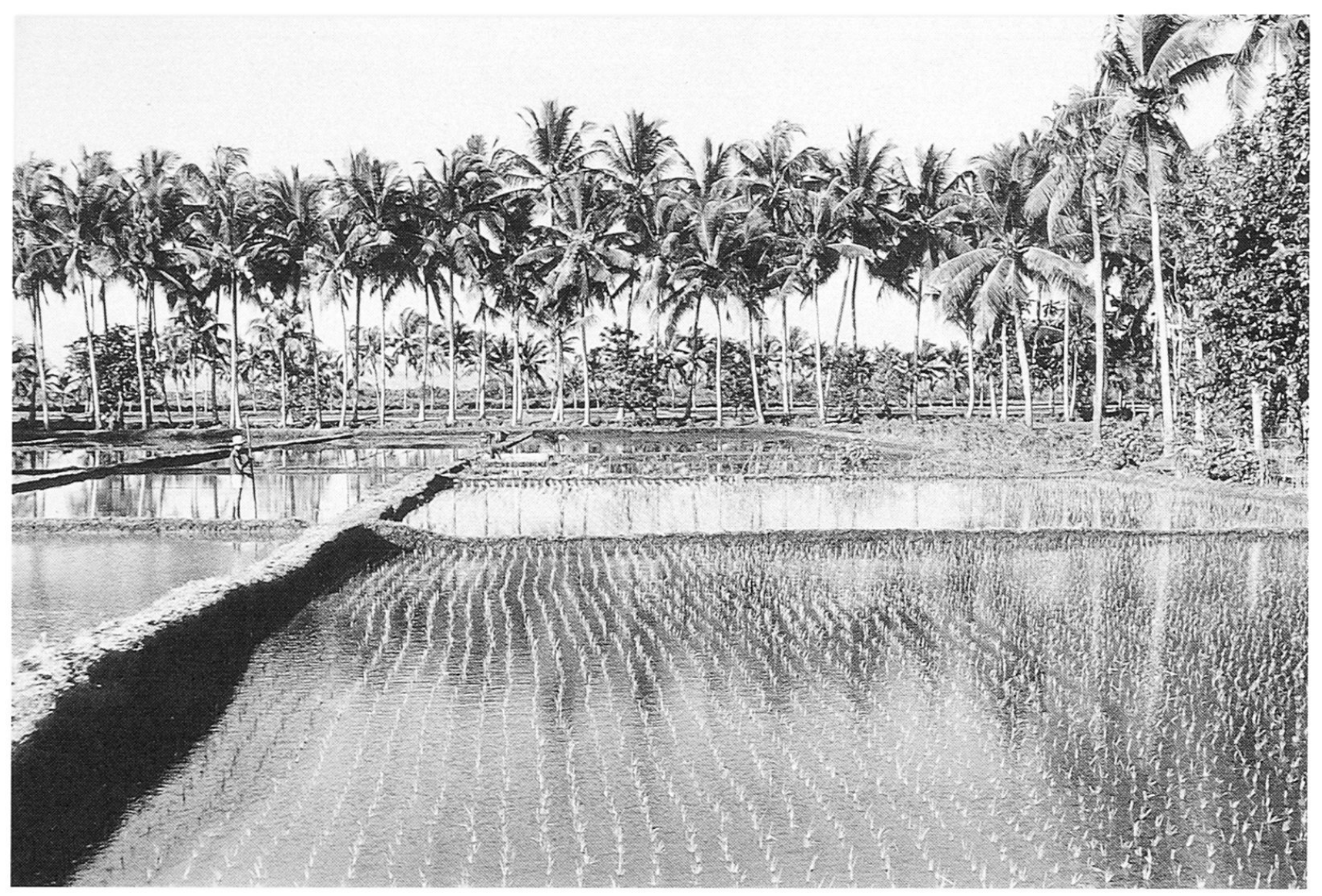

Fig. 3 Naßreisparzellen in der Alluvialebene von Südbali. (Foto A. Leemann)

seln und wird den sogenannt "Inneren Inseln» Indonesiens zugerechnet. Im Gegensatz zu den «Äußeren Inseln» zeichnen sich «Innere Inseln» durch hohe Bevölkerungszahlen bei knappen Landressourcen aus. Als weltweit bekanntestes Eiland Indonesiens ist die «Insel der Götter» nicht nur die Provinz mit der größten Forscherdichte, sondern von der Zentralregierung der Republik Indonesiens auch erfolgreich zum Zugpferd der touristischen Erschließung des großen Archipels erkoren worden.

Die vorliegenden Artikel von Zürcher Geographen nehmen Bezug auf die «klassische» Organisation verschiedener balinesischer Gemeinschaften (A. Leemann), auf den sozio-kulturellen Wandel peripherer bäuerlicher Gesellschaften (S. Wälty) bzw. auf institutionelle Anpassungen und Veränderungen in der boomenden Primatstadt Denpasar (A. Tarnutzer). Inhalt des Aufsatzes von R. Lünsmann ist die Erfassung der occupational multipli- city von bedürftigen Teilbauernfamilien im touristisch unberührten Ostbali. Tradierte und moderne Meeresnutzungsformen sind Thema des Artikels von N. Backhaus.

Albert Leemann

\section{Literatur}

LEEMANN, A. (1979): Bali, Innsbruck, Frankfurt a. M.

LEEMANN, A., TARNUTZER, A. WÄLTY, S. (1978): Bali: Tourismus und Entwicklung. In: Materialien zum Internationalen Kulturaustausch, Band 28, Stuttgart, Tübingen, 179-196.

NOTHOFER, B., PAMPUS, K.-H. (1988): Bahasa Indonesia. Indonesisch für Deutsche, Teil 1, Heidelberg.

RÖLL, W. (1979): Indonesien, Entwicklungsprobleme einer tropischen Inselwelt, Stuttgart.

UHLIG, H. (1988): Südostasien, Frankfurt a. M. 